\title{
Surprisingly benign histopathology in a case of malignant looking ovary
}

\author{
Rachna Agarwal, Alpana Singh, AG Radhika, Garima Vats \\ Correspondence: Dr Rachna Agarwal, Professor, Department of Obstetrics and \\ Gynaecology, University College of Medical Sciences \& GTB Hospital, Delhi - 110095, \\ India; Email - rachna_anila@yahoo.co.in
}

Distributed under Attribution-NonCommercial-ShareAlike 4.0 International (CC BY-NC-SA 4.0)

\begin{abstract}
Xanthogranuloma is a non-neoplastic presentation of chronic inflammation commonly seen in gallbladder, kidneys and rarely seen in genital organs. Herein, we report a case of xanthogranulomatous oophoritis in a 45 year female who presented with lower abdominal pain and backache. There was an ill defined mass around 14 weeks size of gravid uterus. USG and CECT scan of abdomen confirmed it to be enlarged multiloculated right ovary $7.2 \times 6.5 \times 6.5 \mathrm{cms}$ with multiple enhancing thick septations. CA125, CA19-9 and LDH were raised. The mass was clinically and radiologically misdiagnosed as ovarian neoplasm. Staging laparatomy was done. Histopathological findings revealed characteristics features of xanthograulomatous oophoritis. Xanthogranulomatous oophoritis should be kept in mind while dealing with cases of ovarian tumors to prevent misdiagnosis of malignancy and to avoid radical surgeries.
\end{abstract}

Keywords: Ovarian neoplasm, xanthograulomatous inflammation, xanthograulomatous oophoritis.

Xanthograulomatous inflammation is an uncommon type of chronic inflammation in which the affected organ is destroyed and is replaced by large number of lipid laden macrophages with an admixture of lymphocytes, plasma cells, multinucleated giant cells and neutrophils ${ }^{1}$. The most common affected organs are the kidneys and gall bladder followed by anorectal area, bone, stomach and testes ${ }^{2}$. The female genital tract involvement is rare and mostly confined to endometrium ${ }^{3}$. However, involvement of vagina, cervix, fallopian tube and ovary has also been documented. Only few cases involving the ovary have been reported upto date ${ }^{3}$. Herein, we report a case of xanthogranulomatous oophoritis in a 45 year female who was clinically and radiologically misdiagnosed as ovarian neoplasm. Histopathological findings revealed characteristics features of xanthograulomatous oophoritis.

\section{Case report}

A 45 years old female $\mathrm{P}_{4} \mathrm{~L}_{4} \mathrm{~A}_{2}$ presented with lower abdominal pain and backache since 8 days. On per abdominal examination, there was an ill defined mass around 14 wks size gravid uterus arising from the pelvis and occupying whole of lower abdomen extending to right side. Per vaginal examination revealed same mass in midline and extending to right adnexa, firm, non tender and with restricted mobility. Uterus was felt separately

Received: $10^{\text {th }}$ July 2018. Accepted: $23^{\text {rd }}$ Decmber 2018.

Agarwal R, Singh A, Radhika AG, Vats G. Surprisingly benign histopathology in a case of malignant looking ovary. The New Indian Journal of OBGYN. 2019; 5(2): 142-5 
and left adnexa were normal. Pelvic ultrasound showed evidence of an $8.1 \times 6.7 \mathrm{cms}$ complex cystic lesion in right ovary with solid components and no free fluid in abdomen. Contrast enhanced computed tomography (CECT) scan of abdomen also confirmed it to be enlarged multiloculated right ovary, $7.2 \times 6.5 \times 6.5 \mathrm{cms}$ with multiple enhancing thick septations. Left ovary was normal. Rectosigmoid bowel loops adjacent to the ovarian parenchyma showed mild peribowel fat strand. Hematological investigations showed $\mathrm{Hb} 10.1 \mathrm{gm} \%$, TLC 12,400/cumm, platelet count 1.37 lakhs/ cumm and ESR of $54 \mathrm{~mm} / \mathrm{hr}$. Liver function tests, kidney function tests, coagulation profile and urine routine microscopy were within normal limits. CA125, CA19-9 and LDH were raised $(146.8 \mathrm{U} / \mathrm{ml}, \quad 191.3 \mathrm{U} / \mathrm{ml}$ and $1124 \mathrm{U} / \mathrm{ml}$ respectively). Pulmonary function tests showed

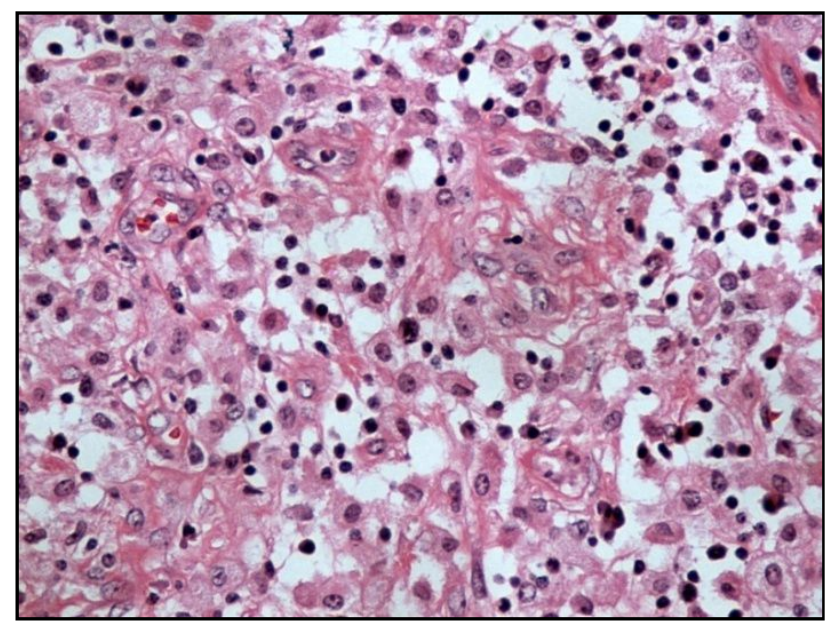

Figure1: Histopathology showing xanthograulomatous oophoritis with endometriosis

obstructive pattern. With presumptive diagnosis of ovarian malignancy patient was taken for staging laparotomy. Intraoperatively $8 \times 10 \mathrm{cms}$ right tuboovarian mass was noted that was adherent to bowel. Left ovary was mildly enlarged. Mild ascites was present. Total abdominal hysterectomy, bilateral salpingo-oophorectomy and infracolic omentectomy was done after 4 hours of meticulous dissection. No residual tumor was left. Grossly, the external surface was smooth and cut section showed multiple solid and cystic areas. Cysts contained yellowish pus like fluid. Solid areas showed yellowish appearance and areas of necrosis. Histopathology revealed it to be a case of xanthograulomatous oophoritis (figure 1) with endometriosis. Three units of blood were transfused. She developed pus discharge from wound on postoperative day 3 which was treated with antibiotics. Resuturing of abdominal wound was carried out on postoperative day 20. She was discharged on postoperative day 22 .

\section{Discussion}

Kunakemakron was the first to describe xanthogranulomatous inflammation of serosa of uterus, left fallopian tube and ovary in his report of inflammatory pseudotumor in the pelvis in $1976^{4}$. To date, very few cases of xanthogranulomatous oophoritis have been reported.

The exact pathogenesis of xanthogranulomatous inflammation is still unclear. Proposed etiologic factors include chronic bacterial infections, ineffective antibiotic therapy, ineffective clearance of bacteria by phagocytes, abnormality in macrophage, gram-negative or anerobic bacteria as in genitourinary tract infections, foreign material such as retained suture material and long standing pelvic inflammatory disease ${ }^{5}$. Bacteria like bacteroides fragilis, escherichia coli, staphylococcus aureus and salmonella typhi can be considered in the pathogenesis of xanthogranulomatous oophoritis ${ }^{6}$. Punia et al. have reported a case of xanthogranulomatous oophoritis and salpingitis as late sequelae of inadequately treated staphylococcal pelvic inflammatory disease ${ }^{7}$. Singh et al reported cervical xanthogranuloma associated with tuberculosis ${ }^{8}$. Shukla et al. have reported a case of xanthogranulomatous oophoritis associated with primary infertility and endometriosis ${ }^{9}$. Premature ovarian failure as rare sequelae of xanthogranulomatous inflammation has also been reported ${ }^{10}$. Cases of xanthogranulomatous inflammation of ovary with ovarian hemangioma ${ }^{11}$, secondary to diverticulitis ${ }^{12}$, as an unusual cause of tuboovarian abscess ${ }^{1}$, association with endometriosis and uterine leiomyoma ${ }^{13}$, association with diabetes mellitus ${ }^{14}$, secondary to talcum powder ${ }^{15}$, presenting as an unusual complication of typhoid ${ }^{16}$ and following uterine artery embolization ${ }^{17}$ have been reported.

The average age of patients with oophoritis 38.5 years (range 23-72) and the youngest case reported was of 18 years ${ }^{18}$. Clinical presentations include anemia, anorexia, 
fever, menorrhagia and pain abdomen. Gynaecological examination can reveal adnexal mass with tenderness. Laboratory tests can show elevated erythrocyte sedimentation rate and increased white blood cell count ${ }^{5}$. Clinically and radiologically xanthogranulomatous inflammation may mimic ovarian tumor ${ }^{19}$. CT and MR imaging findings are usually nonspecific. In our patient, ovarian tumour was suspected on the basis of ultrasonography. However, the correct diagnosis required the help of histopathological study. In Xanthogranulomatous inflammation, the affected ovary can be replaced by a well circumscribed, solid, yellowish, lobulated mass and can also present with cystic lesion at times. In our case, involved ovary has been found to be enlarged and solid with yellowish areas on cut surface. The yellowish colour of this condition on gross examination is due to foam cells ${ }^{20}$. Microscopically it is characterized by a massive infiltration of the affected tissues by lipid laden histiocytes known as Xanthoma cells admixed with inflammatory cells consisting of lymphocytes, plasma cells and neutrophils and similar features have been seen in our case on microscopy ${ }^{2}$.

Because of the presence of foamy histiocytes, malakoplakia should be considered in the differential diagnosis of xanthogranulomatous inflammation. According to Wather, malakoplakia and xanthogranulomatous inflammation are identical chronic inflammatory diseases and they have a common pathogenetic pathway ${ }^{2}$. In xanthogranulomatous oophoritis, the cytoplasmic concentric calcified Michaelis-Gutmann bodies are not seen which can be seen in malakoplakia. In our case the Michaelis-Gutmann bodies were not seen ${ }^{2}$. Due to the rarity of the condition, xanthogranulomatous oophoritis can be confused with secondary lymphoma or leukaemia if the lesion is mainly with focal scattered lymphocytes. Sclerosing stromal tumor is also kept in the differential diagnosis when there are small amount of obvious fibrosis and foam cells.

In our case, predominant infiltration with foamy hystiocytes, few areas of sclerosis have been seen with mixed inflammatory cells. Frozen section is also helpful in the diagnosis of xanthogranulomatous inflammation and further intra operative management ${ }^{21}$. Immuno histochemistry and the markers including CD68 (foam cells positive), CD3 (T lymphocyte marker) and CD20 (B lymphocytes marker) are also useful in establishing the diagnosis ${ }^{20}$. In our case, we have not studied immunohistochemistry, because the histopathological features confirmed the diagnosis. Surgery is the treatment of choice. Awareness of this inflammatory lesion can prevent extensive surgery ${ }^{6}$.

Treatment of choice for xanthogranulomatous oophoritis is oophorectomy. Antibiotic therapy has been attempted but it has not succeeded in reducing ovarian mass ${ }^{4}$.

\section{Conclusion}

Xanthogranulomatous oophoritis should be kept in mind while dealing with cases of ovarian tumors to prevent misdiagnosis of malignancy and to avoid radical surgeries.

\section{Conflict of interest: None. Disclaimer: Nil.}

\section{References}

1. Kim SH, Kim SH, Yang DM, Kim KA. Unusual Causes of Tubo-ovarian Abscess: CT and MR Imaging Findings 1. Radiographics. 2004; 24(6): 1575-89.

2.Kalloli M, Bafna UD, Mukherjee G, Devi UK, Gurubasavangouda, Rathod PS. A rare xanthogranulomatous oophoritis presenting as ovarian cancer. Online Journal of Health and Allied Sciences. 2012; 11(2): 11.

3.Shukla S, Pujani M, Singh SK, Pujani M.

Xanthogranulomatous oophoritis associated with primary infertility and endometriosis. Indian Journal of Pathology and Microbiology. 2010; 53(1):197.

4.Kunakemakorn P, Ontai G, Balin H. Pelvic inflammatory pseudotumor: a case report. American journal of obstetrics and gynecology. 1976; 126(2): 286-7.

5.Gray Y, Libbey NP. Xanthogranulomatous salpingitis and oophoritis: a case report and review of the literature.

Archives of pathology \& laboratory medicine. 2001; 125(2): 260-3.

6.Raj JA, Jagadeesha M, Naveen S, Ramachandra U. Xanthogranulomatous oophoritis: pathologic findings with clinical correlation. Journal of the Indian Medical Association. 2012; 110(9): 653-4.

7.Punia RS, Aggarwal R, Mohan H. Xanthogranulomatous oophoritis and salpingitis: late sequelae of inadequately treated staphylococcal PID. Indian journal of pathology \& microbiology. 2003; 46(1): 80-1. 
8.Singh A, Vats G, Radhika AG, Meena P, Radhakrisnan G. Cervical xanthogranuloma in a case of postmenopausal pyometra. Obstetrics \& Gynecology Science. 2016; 59(5): 411-4.

9.Shukla S, Pujani M, Singh SK, Pujani M. Xanthogranulomatous oophoritis associated with primary infertility and endometriosis. Indian Journal of Pathology and Microbiology. 2010; 53(1): 197.

10.Singh N, Dadhwal V, Sharma KA, Mittal S. Xanthogranulomatous inflammation: a rare cause of premature ovarian failure. Archives of gynecology and obstetrics. 2009; 279(5): 729-31.

11.Shashikala K, Sharmila PS, Sushma TA. Ovarian Haemangioma with Synchronous Xanthogranulomatous Inflammation-A Rare Pathological Finding. International Journal of Health Sciences and Research (IJHSR). 2013; 3(5):116-9.

12.Altanis S, Raweily E, Katesmark M.

Xanthogranulomatous endometritis and oophoritis secondary to diverticulitis. A rare cause of postmenopausal bleeding. Journal of Obstetrics and Gynaecology. 2007; 27(7): 746-7.

13.Abeysundara PK, Padumadasa GS, Tissera WG, Wijesinghe PS. Xanthogranulomatous salpingitis and oophoritis associated with endometriosis and uterine leiomyoma presenting as intestinal obstruction. Journal of Obstetrics and Gynaecology Research. 2012; 38(8):1115-7.

14.Chou SC, Wang JS, Tseng HH. Malacoplakia of the ovary, fallopian tube and uterus: a case associated with diabetes mellitus. Pathology international. 2002; 52(12): 789-93.

15.Chouairy CJ, Hajal EA, Nehme YA.

Xanthogranulomatous oophoritis secondary to talcum powder. Case report and review of the literature. Le Journal médical libanais. The Lebanese medical journal. 2012; 60(3): 169.

16.Singh UR, Revathi G, Gita R. Xanthogranulomatous oophoritis: an unusual complication of typhoid. Journal of Obstetrics and Gynaecology. 1995; 21(5): 433-6.

17.Singh N, Tripathi R, Mala YM, Arora S. Xanthomatous oophoritis following uterine artery embolisation: successful conservative surgical management with favourable outcome. BMJ case reports. 2013; 2013: bcr2013010184.

18.Hemalatha AL, Rao S, Deepak KB, Gayathri MN, Manjunath BS, Rathna S. Xanthogranulomatous salpingooophoritis: a rare entity at an exceptional site. Indian Journal of Pathology and Microbiology. 2007; 50(3): 607.

19. Mahesh Kumar U, Potekar RM, Yelikar BR, Pande P. Xanthogranulomatous oophoritis-masquerading as ovarian neoplasm. Asian J Pharm and Sci. 2012; 2(2): 308-9.

20.Zhang XS, Dong HY, Zhang LL, Desouki MM, Zhao C. Xanthogranulomatous inflammation of the female genital tract: report of three cases. J Cancer. 2012; 3: 100-6.

21.Yener N, Ilter E, Midi A. Xanthogranulomatous salpingitis as a rare pathologic aspect of chronic active pelvic inflammatory disease. Indian Journal of Pathology and Microbiology. 2011; 54(1): 141.

\footnotetext{
Rachna Agarwal ${ }^{1}$, Alpana Singh ${ }^{2}$, AG Radhika ${ }^{3}$, Garima Vats ${ }^{4}$

${ }^{1}$ Professor; ${ }^{2}$ Associate Professor; ${ }^{3}$ Senior Specialist;

${ }^{4}$ Senior Resident, Department of Obstetrics and Gynaecology, University College of Medical Sciences \& GTB Hospital, Delhi - 110095, India.
} 